\title{
EVOLUÇÃO DA PESQUISA SOBRE INTENÇÃO EMPREENDEDORA: UMA REVISÃO SISTEMÁTICA
}

Jessyca Lages ${ }^{1}$

Rubens Carlos Rodrigues ${ }^{1}$

José Milton De Sousa Filho ${ }^{1}$

${ }^{1}$ Universidade de Fortaleza - UNIFOR 


\section{Evolução da pesquisa sobre intenção empreendedora: uma revisão sistemática}

Resumo: Esta revisão de literatura tem por objetivo atualizar a pesquisa desenvolvida pelos autores Liñan e Fayolle sobre Intenção Empreendedora (IE), os quais analisaram 409 artigos publicados entre os anos de 2004 a 2013 e categorizaram as principais áreas de especialização da IE, identificando uma série de temas de pesquisa relacionadas a estas, possibilitando a ordenação e sistematização do conhecimento produzido nesta temática. Pesquisa efetuada nas bases de dados Scopus e Web of Science (Web Science Citation Index) sendo analisados 378 artigos publicados entre os anos de 2014 a 2018, dos quais 269 estavam relacionados ao tema. Os resultados demonstram que a categorização efetuada por Liñan e Fayolle são ainda suficientes e abrangentes para classificar os estudos realizados no presente período, no entanto, é necessário acrescentar mais uma categoria no Grupo 6, de novas pesquisas, o subgrupo de empreendedorismo de startup.

Palavras-chave: Intenção Empreendedora. Revisão de literatura. Lacunas de pesquisa.

\section{Introdução}

A teoria sobre Intenção Empreendedora (IE) ganhou notoriedade a partir da união da Teoria do Comportamento Planejado (TCP) de Ajzen (1991) com o empreendedorismo de Shapero (1984). No entanto, é com Krueger e Carsud (1993) que estes assuntos se convergem e aplicam a TCP aos estudos de IE.

Desde então, as pesquisas nesta área cresceram de forma exponencial, no entanto, de forma desordenada em todo o mundo. Não sendo possível, por exemplo, comparar intenções empreendedoras de diferentes locais e contribuir com substancial avanço teórico para o crescimento da área, válido em qualquer localidade. De forma que se detectou uma tendência dos autores a recomeçarem em cada pesquisa (LIÑAN; FAYOLLE, 2015).

Em 2015, os pesquisadores Liñan e Fayolle publicaram uma pesquisa que categorizou todos os estudos que abordaram sobre IE, prestando como alicerce para o crescimento do tema. Os autores analisaram 409 artigos, relacionados a IE, publicados entre os anos de 2004 a 2013, efetuando análise temática e divisão das pesquisas em grupos e subgrupos específicos, nos quais emergiram seis grupos, sendo cinco grupos principais e um sexta relacionado a novas pesquisas ainda em expansão. Com isto, identificou-se o retrato da pesquisa em intenção empreendedora e evidenciou novas lacunas de estudo.

No entanto, a pesquisa de Liñan e Fayolle foi realizada até o ano de 2013, e nenhuma outra pesquisa foi encontrada que a atualizasse, sendo então o objetivo da presente pesquisa analisar os artigos publicados entre os anos de 2014 a 2018 que abordam Intenção Empreendedora, conforme o modelo apresentado por Liñan e Fayolle (2015). De forma que o pressuposto deste estudo é o surgimento de novos grupos ou subgrupos, bem como a emergência de novas lacunas de pesquisas a serem abordadas.

Para reproduzir a mesma pesquisa de Liñan e Fayolle (2015) utilizou-se a mesma metodologia aplicada. Uma pesquisa inicial nas bases de dados Scopus e Web of Science (Web Science Citation Index). Seguido pela integração de resultados e exclusão dos documentos 
duplicados. Por fim, leitura dos 378 artigos encontrados para categorização em grupos e subgrupos.

Os resultados demonstram que a categorização efetuada por Liñan e Fayolle (2015) são ainda suficientes e abrangentes para classificar os estudos realizados de 2014 a 2018 , no entanto, é necessário acrescentar mais uma categoria no grupo 6 de novas pesquisas, o subgrupo de empreendedorismo de startup.

Esta pesquisa divide-se em um breve referencial teórico que abordará as teorias que sustentam a intenção empreendedora. Logo após o percurso metodológico para o desenvolvimento da pesquisa, seguido dos resultados e discussões que expõem os avanços da área de intenção empreendedora e os novos grupos e subgrupos sugeridos pelos autores.

\section{Referencial Teórico}

As pesquisas sobre Intenção Empreendedora ganharam relevância no mundo e no Brasil a partir da contribuição da psicologia por meio da Teoria do Comportamento Planejado (TCP) de Ajzen e Fishbein (1980) e convergem com o empreendedorismo de Shapero (1984).

A TCP surgiu da lacuna do estudo de atitudes gerais e Teoria da Agregação em predizer comportamentos específicos dirigidos ao alvo da atitude. De forma que a TCP surgiu como uma teoria projetada para prever e explicar o comportamento humano em contextos específicos (AJZEN, 1991).

O fator central da TCP é a intenção do indivíduo de realizar determinado comportamento. Esta intenção é o indício de quanto as pessoas estão dispostas a tentar para realizar determinado comportamento. Como regra geral, quanto mais forte a intenção de se envolver em um comportamento, maior a probabilidade de seu desempenho. No entanto, um comportamento só pode ser expresso se estiver sobre controle volitivo, ou seja, se a pessoa puder realmente decidir se executa ou não o comportamento. Alguns fatores podem ser impeditivos para esta tomada de decisão, tais como as oportunidades e recursos (tempo, dinheiro, habilidades, cooperação e outros), conforme a Figura 1 (AJZEN, 1991).

\section{Figura 1- Teoria do Comportamento Planejado}

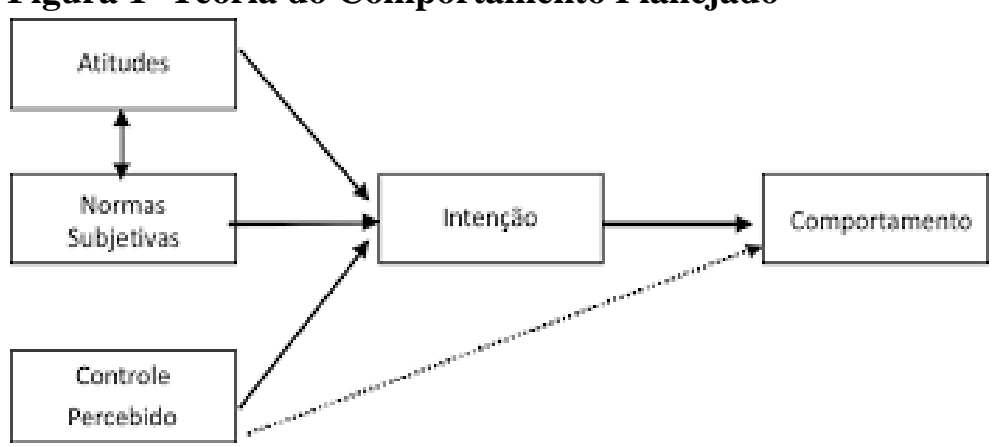

Fonte: Tradução efetuada pelos autores baseado no artigo de Ajzen (1991).

As intenções de realizar comportamentos de diferentes tipos podem ser previstas conforme a atitudes em relação ao comportamento, normas subjetivas e controle comportamental percebido; e essas intenções juntamente com a percepção de controle comportamental, são responsáveis por considerável variação no comportamento real. Este 
controle comportamental deve ser realista, pois se os requisitos e recursos disponíveis mudarem ou surgirem novos elementos desconhecidos, ele será alterado (AJZEN, 1991).

A teoria de Ajzen começou a ser aplicada em outras áreas, dentre elas, o empreendedorismo, sendo Krueger e Carsud (1993) os responsáveis por tornar a TCP a teoria de referência na pesquisa de intenção empreendedora. Desde então, novas pesquisas foram sendo realizadas, ocorrendo a criação e aplicação dos modelos de intenção empreendedora. Krueger e Carsud (1993) defendem que os modelos de intenções permitem entender melhor o impacto de vários antecedentes do surgimento de uma organização, não só identificar o que surgiu, mas como surgiu.

Krueger e Carsud (1993) argumentam que a intenção é extremamente útil para os fenômenos que são raros, ou seja, apresentam uma baixa taxa de ocorrência, como o empreendedorismo. De forma que estudar as intenções destes fenômenos revela insights significativos e permitem uma melhor compreensão das hipóteses sobre os comportamentos empreendedores. Para isto, Krueger e Carsud (1993) desenvolveram modelo da TCP aplicado a IE, conforme a Figura 2.

\section{Figura 2- Modelo da Teoria do Comportamento Planejado aplicado a Intenção Empreendedora}

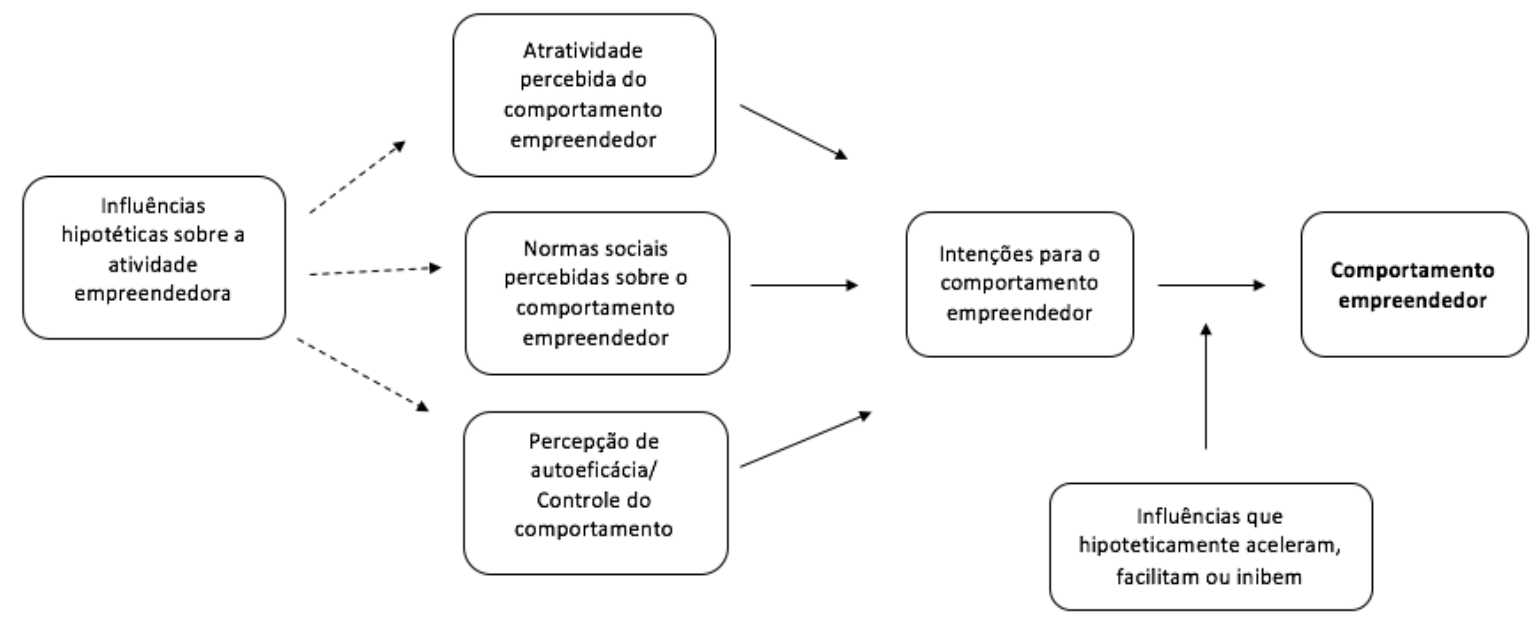

Fonte: Krueger e Carsud (1993).

O modelo proposto explica o comportamento empreendedor através das intenções para o comportamento de empreender que são influenciadas pela atratividade percebida do comportamento empreendedor, pelas normas sociais percebidas sobre o comportamento empreendedor e pela percepção de auto eficácia deste comportamento.

Segundo Liñan e Fayolle (2015), a partir de então, a pesquisa sobre IE expandiu-se em todo o mundo. Os novos estudos abordaram testes da teoria, utilização de novas variáveis, novas metodologias, diferentes intenções, dentre outras nuances. No campo empírico, questionários e escalas de medição foram elaboradas por diversos autores, tais como Liñan e Chen (2009), com o questionário de atitude e intenção empreendedora de estudantes universitários, o qual pode ser aplicado em países com diferentes culturas com o objetivo de serem comparáveis utilizando como base a TCP. 
Liñan e Fayolle (2015) sistematizaram todos os estudos realizados e categorizaram as pesquisas em grupos e subgrupos, conforme apresentado na Figura 3.

\section{Figura 3 - Reprodução da categorização de estudos sobre intenção empreendedora}

GRUPO 1: Modelo
central de intençä̊
empreendedora

Fonte: Liñan e Fayolle (2015)

O Grupo 1 agrega os artigos com temas relacionados ao modelo central da IE, como as questões metodológicas e teóricas que afetam o modelo. E tem como subtemas o teste geral da teoria, as pesquisas que abordam intenções específicas, os novos quadros teóricos, as variáveis adicionais, as pesquisas de configurações de antecedentes motivacionais e as que abordam a metodologia. Neste grupo Liñan e Fayolle (2015) destacaram como pesquisas mais relevantes, os seguintes autores: Zhao et al(2015), Hmieleski e Corbett (2006), Van Gelderen et al (2008), Liñan e Chen (2009) e Thompson (2009).

No Grupo 2 agregou-se pesquisas cujas variáveis de estudo abordam temas de nível pessoal, ou seja, incluiu artigos que tratam sobre os traços pessoais na intenção de empreender, as variáveis psicológicas, as variáveis demográficas e as experiências em IE. Agregando ainda publicações sobre questões de gênero, barreiras percebidas e subamostras 
específicas, como por exemplo, amostras com estudantes e profissionais. De forma que Liñan e Fayolle (2015) referenciaram Segal et al (2005), Lee e Wong (2004), Sequeira (2007), Gird e Bagraim (2008) e outros como destaque deste grupo.

Conforme Liñan (2010), novas variáveis testadas por pesquisadores podem explicar a intenção e o comportamento do empreendedor, como o gênero (MINNITI; NARDONE, 2007), idade (LEVESQUE; MINNITI, 2006) ou experiência de trabalho (COOPER; PARK, 2008). Em 2007, Kor expôs uma nova teoria que define o conhecimento pessoal do empreendedor como influência significativa na decisão de empreender, ou seja, uma teoria que se concentra nos indivíduos, seus conhecimentos, recursos e habilidades.

A educação empreendedora está alocada no Grupo 3 e contempla pesquisas que avaliam os programas de educação, tanto seus resultados quanto sua evolução, os vínculos destes programas com a IE. Também fazem parte os artigos que abordam as características dos participantes, que comparam os programas de educação empreendedora e por fim ainda sugerem como estes devem ser realizados. Liñan e Fayolle (2015) referenciam Franke e Luthje (2004), Pittaway e Cope (2007), Souitaris et al (2007) e Fayyolle et al. (2006).

No Grupo 4 há o enfoque da influência de ambientes regionais, culturais ou institucionais em casos de intenções empreendedoras. As pesquisam abordam em seus subtemas os estudos transculturais, as experiências culturais, as variáveis institucionais e os estudos que trazem uma abordagem ecológica. Liñan e Fayolle (2015) referenciam os principais autores deste grupo, são eles: Kristiansen e Indarti (2004), Veciana et al. (2005), Pillis e Reardon (2007) e Engle et al. (2010).

O Grupo 5 analisa o processo empreendedor e o vínculo da intenção e do comportamento. Os subgrupos trazem pesquisas relacionadas a estudos longitudinais e variáveis que afetam o processo.

Liñan e Fayolle (2015) também enfocam um sexto grupo que traz novas pesquisas da área relacionadas ao empreendedorismo sustentável, ao empreendedorismo social e a outras temáticas.

A IE é uma área de estudo consolidada no empreendedorismo e nos últimos anos vem contribuindo para o surgimento de novas questões de pesquisa. Este mapeamento do avanço da área foi realizado por Liñan e Fayolle (2015) através da categorização e análise dos estudos científicos e apontaram os novos caminhos. De forma que, desde então, as pesquisas avançaram e o modelo de intenção foi aplicado a diversas situações.

\section{Metodologia}

A pesquisa classifica-se como descritiva, quanto aos objetivos propostos e como levantamento bibliométrico, quanto à abordagem do problema, pois, conforme Creswell (2007), busca colher informações bibliográficas publicadas sobre o tema.

Os dados foram pesquisados no mês de abril de 2019, motivo este que os artigos publicados no ano de 2019 terem sido excluídos, dado que é o ano em curso. O procedimento de coleta de dados foi seccionado em três partes: o período abrangeu o período de 2014 a 2018, os últimos cinco anos; aplicação da pesquisa booleana utilizando o elemento and com as mesmas palavras-chaves que Liñan e Fayolle (2015) utilizaram as quais são: "entrep*" e "intent*", visando identificar artigos que incluíssem as duas palavras simultaneamente no 
título, no resumo ou nas palavras-chave de cada artigo; finalizando com a formação do portfólio dos artigos componentes da amostra.

Foram efetuadas buscas nas seguintes bases de dados: Web of Science da Thomson Reuters e Scopus da Elsevier. Na base Web of Science foram encontrados 299 artigos, ao passo que na base Scopus, 180 artigos. Para integrar todos os resultados e eliminar artigos duplicados utilizou-se o software Mendeley Desktop, sendo 101 artigos excluídos e um total de 378 documentos foram inicialmente identificados. Para estes, foram realizados download do artigo buscando permitir a análise mais aprofundada quando o resumo do mesmo não contivesse informações suficientes para poder classificá-lo.

Realizou-se o preenchimento manual de planilha eletrônica, com os seguintes dados dos artigos: autores, ano, título do artigo, nome do periódico e detalhes da publicação, visando complementar a lista de Liñan e Fayolle (2015).

Todos os 378 artigos foram lidos na íntegra por um dos autores para buscar categorizar ou eliminar do estudo as publicações que não estavam relacionadas ao tema aqui pesquisado, já que alguns temas abordados nas pesquisas pertencem a diferentes categorias e a aplicação de modelos de intenção empreendedora foi muitas vezes utilizada, erroneamente, a grupos de empresários já consolidados. Sendo então identificados e excluídos 109 que tratavam de temas díspares e desviavam do assunto, compondo assim a amostra a ser estudada o total de 269 artigos, os quais foram classificados e agrupados utilizando, preferencialmente, os mesmos temas identificados por Liñan e Fayolle (2015), caso não fosse possível, alocava-se em uma nova subcategoria.

A análise dos dados deu-se com o auxílio de planilhas eletrônicas, permitindo assim a tabulação e apresentação de gráficos e tabelas.

\section{Resultados e discussões}

Após a análise de todos os 269 artigos e sua respectiva classificação em grupos e subgrupos, iniciou-se a identificação dos artigos com maior número de citações dentro de sua amostra. Conforme Liñan e Fayolle (2015), sendo o parâmetro utilizado para isto a quantidade de 13 ou mais citações. Na presente pesquisa tal valor foi igual a 10, sendo então identificados 17 artigos, conforme demonstrado na Tabela 1.

A Tabela 1 apresenta a classificação dos artigos mais citados por grupo. Como esperado, a maioria deles refere-se ao grupo 1 que aborda questões centrais do modelo, as teorias e a aplicação empírica da intenção empreendedora. Por exemplo, Acs et al (2016) adiciona variáveis a sua pesquisa, e relaciona o efeito das políticas públicas no incentivo aos indivíduos que tem intenção de empreender. Biraglia \& Kadile (2017) também adiciona variáveis a Teoria do Comportamento Planejado e investiga o papel da paixão empreendedora e da criatividade nos antecedentes da intenção de empreender.

Já Miranda et al (2017), aplica a TCP de Ajzen (1991) a 1.178 acadêmicos universitários espanhóis e investiga a intenção destes de empreender. Da mesma forma, Wach \& Wojciechowski (2016) aplica ao ambiente acadêmico polonês, só que a TCP é acrescida de mais uma variável, a atitude em relação ao risco.

Ainda no Grupo 1, Barba-Sánchez e Atienza-Sahuquillo (2018) buscaram identificar a intenção de empreender dos futuros engenheiros e adicionaram a variável de educação empreendedora na pesquisa. Menozzi et al (2015) aplicou a TCP a intenção específica de 
agricultores implementarem práticas sustentáveis relacionadas com a manutenção da área de foco ecológico e com esquemas privados de sustentabilidade.

Tabela 1- Artigos mais citados (Período 2014 a 2018)

\begin{tabular}{|c|c|c|c|}
\hline Categoria do Grupo & Autores & Journal & Citações \\
\hline \multirow{8}{*}{$\begin{array}{l}\text { Grupo 1: Modelo central de Intenção } \\
\text { Empreendedora }\end{array}$} & Acs et al (2016) & SBE & 40 \\
\hline & Biraglia \& Kadile (2017) & JSBM & 20 \\
\hline & Miranda et al (2017) & ERMBE & 19 \\
\hline & Wach \& Wojciechowski (2016) & EBER & 17 \\
\hline & Barba-Sánchez \& Atienza-Sahuquillo (2018) & ERMBE & 17 \\
\hline & Menozzi et al (2015) & BBAE & 16 \\
\hline & Coduras et al (2016) & JIK & 12 \\
\hline & Lanero et al (2015) & AP & 11 \\
\hline Grupo 2: Variáveis de nível pessoal & Welsh et al (2016) & JIK & 12 \\
\hline \multirow{4}{*}{ Grupo 3: Educação Empreendedora } & Piperopoulos \& Dimov (2015) & JSBM & 84 \\
\hline & Maresch et al (2016) & TFSC & 42 \\
\hline & Nabi et al (2018) & SHE & 22 \\
\hline & Welsh et al (2016) & JIK & 15 \\
\hline Grupo 4: Contexto e Instituições & Yousafzai et al (2015) & JSBM & 28 \\
\hline \multirow{3}{*}{ Grupo 6: Novas pesquisas } & Kautonen et al (2015) & ETP & 170 \\
\hline & Bergmann et al (2016) & SBE & 25 \\
\hline & Tran \& Von Korflesch (2016) & APJIE & 12 \\
\hline
\end{tabular}

Nota: AP(1): Anales de Psicologia; APJIE (1): ASIA PACIFIC JOURNAL OF INNOVATION AND ENTREPRENEURSHIP; BBAE (1): BIO-BASED AND APPLIED ECONOMICS; EBER (1): ENTREPRENEURIAL BUSINESS AND ECONOMICS REVIEW; ERMBE (2): European Research on Management and Business Economics; ETP(1): ENTREPRENEURSHIP THEORY AND PRACTICE; JIK (3): JOURNAL OF INNOVATION \& KNOWLEDGE; JSBM (3): JOURNAL OF SMALL BUSINESS MANAGEMENT; SBE (2): SMALL BUSINESS ECONOMICS; SHE (1): STUDIES IN HIGHER EDUCATION; TFSC (1): TECHNOLOGICAL FORECASTING AND SOCIAL CHANGE Fonte: Dados da pesquisa (2019).

A pesquisa de Coduras et al. (2016) criou um sistema para calcular as pontuações individuais de prontidão para o empreendedorismo através de variáveis sociológicas, psicológicas e gerenciais-empreendedora. Enquanto Lanero et al. (2015) testa um modelo de escolha de carreira empresarial baseada na Teoria da Carreira Cognitiva Social (TCS) por Lent, Brown e Hackett (1994,2000). A pesquisa foi realizada com 400 estudantes universitários de diferentes áreas do conhecimento.

No Grupo 2, Welsh et al (2016) trabalha as questões de gênero estudando as mulheres turcas empreendedoras incluindo variáveis pessoais, habilidades e conhecimento.

As pesquisas realizadas de Maresh et al (2016) e Welsh et al (2016) foram as mais citadas no Grupo 3. O primeiro analisou o impacto da Educação Empreendedora na intenção de empreender dos estudantes de ciências e engenharia. Enquanto o segundo analisou as 
mudanças que acontecem nas instituições de ensino superior com relação a Educação Empreendedora.

No Grupo 4, o destaque é o subgrupo de variáveis institucionais da pesquisa de Yousafzai et al (2015). O autor desenvolveu uma estrutura de múltiplos níveis que se baseia na noção de enraizamento contextual do empreendedorismo e da teoria institucional. Os resultados sugerem que os pilares institucionais afetam o empreendedorismo de mulheres.

Observa-se que entre os artigos mais citados, nenhum está relacionado ao chamado Grupo 5 que refere-se ao processo de empreendedorismo. Ao passo que a pesquisa realizada por Bergmann et al (2016) abordando o empreendedorismo em startup ganhou uma rápida aceitação na comunidade acadêmica.

$\mathrm{Na}$ Tabela 2 encontram-se os grupos e todas as subcategorias identificadas, com a quantidade de números de trabalhos.

Tabela 02: Grupos e Subgrupos, com quantidade de artigos

\begin{tabular}{|c|c|c|}
\hline Grupo & Subgrupo & Artigos \\
\hline \multirow{6}{*}{$\begin{array}{l}\text { Grupo 1: Modelo central de } \\
\text { Intenção Empreendedora }(124)\end{array}$} & Teste geral da teoria & 59 \\
\hline & Variáveis adicionais & 34 \\
\hline & Intenções específicas & 14 \\
\hline & Configuração de antecedentes motivacionais & 8 \\
\hline & Novo quadro teórico & 5 \\
\hline & Metodologia & 4 \\
\hline \multirow{5}{*}{$\begin{array}{l}\text { Grupo 2: Variáveis de nível } \\
\text { pessoal (44) }\end{array}$} & Questões de gênero & 18 \\
\hline & Fatores internos & 9 \\
\hline & Fatores de personalidade/ psicologia & 8 \\
\hline & Sub amostra específica & 5 \\
\hline & Barreiras percebidas & 4 \\
\hline \multirow{5}{*}{$\begin{array}{l}\text { Grupo 3: Educação Empreen- } \\
\text { dedora (42) }\end{array}$} & Resultados dos programas de educação empreendedora & 21 \\
\hline & Proposta de programa & 10 \\
\hline & Comparações & 5 \\
\hline & Características dos participantes & 4 \\
\hline & Evolução dos programas de educação empreendedora & 2 \\
\hline \multirow{4}{*}{$\begin{array}{l}\text { Grupo 4: Contexto } \\
\text { Instituições (25) }\end{array}$} & Experiências culturais & 12 \\
\hline & Variáveis institucionais & 7 \\
\hline & Estudos transculturais & 5 \\
\hline & Abordagem ecológica & 1 \\
\hline \multirow{2}{*}{$\begin{array}{l}\text { Grupo 5: Processo de empreen- } \\
\text { dedorismo (2) }\end{array}$} & Variáveis que afetam o processo & 1 \\
\hline & Estudos longitudinais & 1 \\
\hline \multirow{4}{*}{ Grupo 6: Novas pesquisas (32) } & Empreendedorismo social & 14 \\
\hline & Empreendedorismo de startups & 9 \\
\hline & Empreendedorismo sustentável & 6 \\
\hline & Outros & 3 \\
\hline
\end{tabular}

Fonte: Dados da pesquisa (2019).

Nota-se que no Grupo 1 os estudos concentraram-se no teste geral da teoria e em testar variáveis adicionais a IE. Já no Grupo 2, as questões de gênero apresentaram grande relevância, seguido pelos fatores internos e psicológicos. No grupo 3, o principal destaque foi 
para os resultados dos programas de educação empreendedora. Os pesquisadores focaram em saber se estes programas realmente impactam na intenção de empreender do estudante. No grupo 4 o destaque foi para as experiências culturais e os estudos transculturais, cada vez mais os pesquisadores comparam as ações de empreendedorismo em diferentes continentes. Por fim, no grupo 6 apresentamos a novidade de uma nova subcategoria.

O empreendedorismo de startup ganhou notoriedade não apenas entre os mais citados, mas também na quantidade de pesquisas acadêmicas e nas novas abordagens deste tema. De forma que foi necessário criar um novo subgrupo no Grupo 6, denominado empreendedorismo de startup, para alocar estas novas pesquisas na área.

Os estudos de empreendedorismo de startup abordaram diversas temáticas, Jha (2018) analisou o ecossistema de startup indiano e detectou a necessidade de criação de valor em oposição à avaliação, necessidade de educar seus jovens empreendedores e desenvolver tolerância para falhas bem intencionadas. Já De Oliveira Lacerda et al (2017) realizou casos exploratórios na incubadora MIDI Tecnológico e utilizou a abordagem Lean Startup para difundir práticas inovadoras em empresas ligadas à incubadoras e criar um ambiente propício para o desenvolvimento das competências dos alunos do curso de administração.

Outro estudo que também aborda o modelo Learn Startup foi realizado por Ekpe et al (2018) com o objetivo de examinar o nível de consciência do modelo e seu efeito sobre as intenções empreendedoras dos jovens da Malásia.

Shirokova et al (2018) desenvolveu pesquisa que analisou a relação entre programação curricular e extra-curricular e as atividades de startup do aluno, resultando em uma correlação negativa ao escopo das atividades de startup. Staniewski \& Awruk (2016) determinaram o valor preditivo da esperança de sucesso de Snyder para a intenção de startup e determinaram que as habilidades e persistência na resolução de problemas, podem ser consideradas um dos fatores subjacentes às intenções de empreender.

Nas Figuras 4,5, 6 e 7 são apresentados os quantitativos de artigos por grupo relacionando os achados da atual pesquisa com os encontrados por Liñan e Fayolle (2015).

Figura 4 - Comparativo entre pesquisa de Liñan e Fayolle (2015) e a atual, Grupo 1

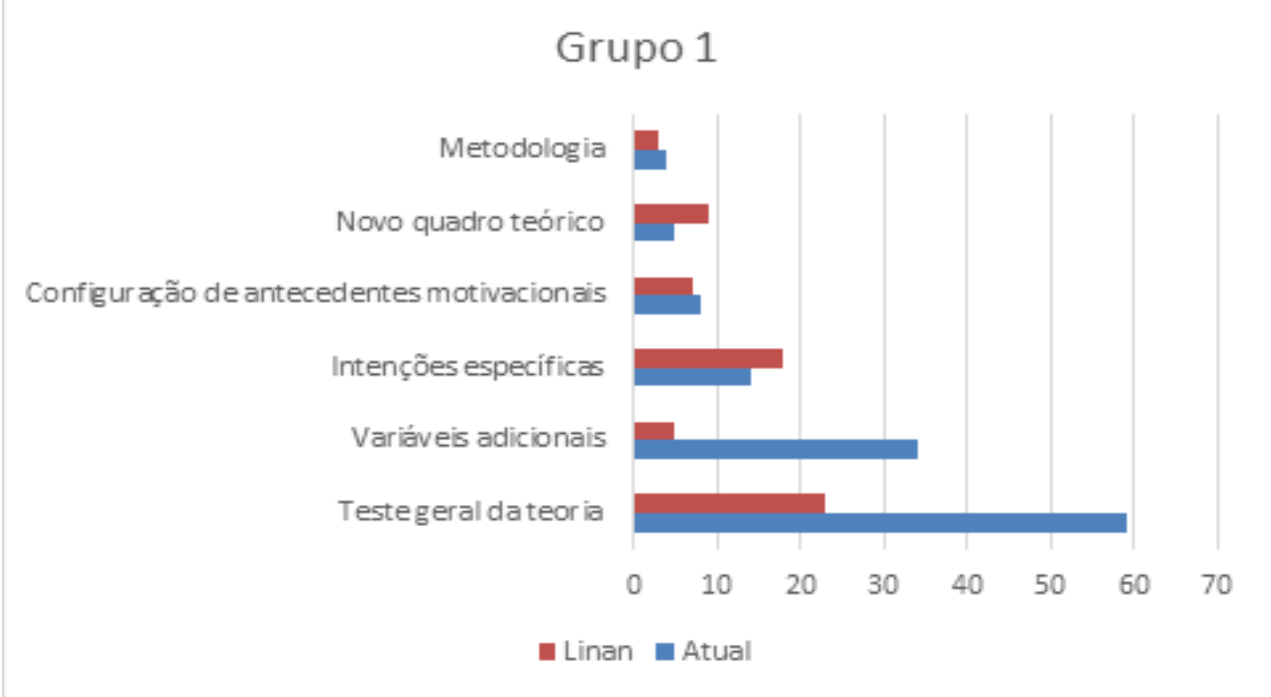

Fonte: Dados da pesquisa (2019). 
Neste sentido, compara-se que revela no Grupo 1 um crescimento acentuado de pesquisas que aplicam o modelo de intenção empreendedora em diferentes ambientes, ou seja, teste geral da teoria através de teste empírico.

Figura 5 - Comparativo entre pesquisa de Liñan e Fayolle (2015) e a atual, Grupo 2

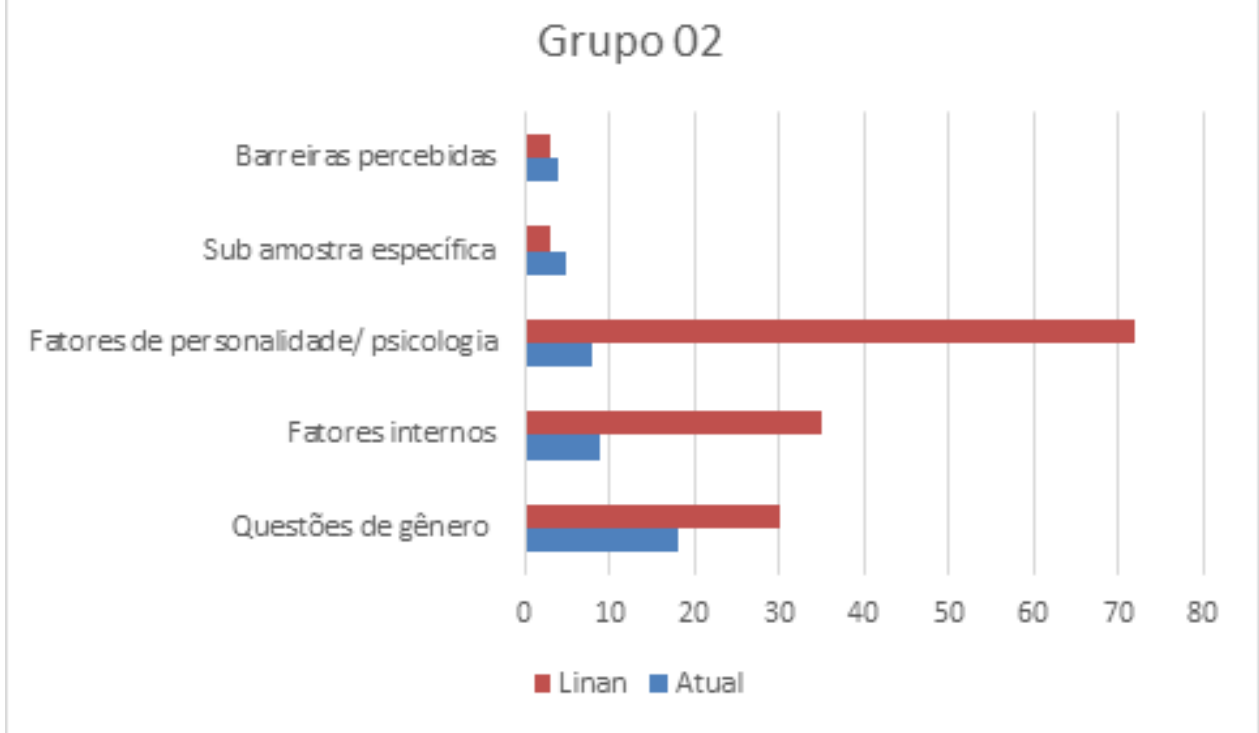

Fonte: Dados da pesquisa (2019).

No Grupo 2, destaca-se a redução de pesquisas relacionadas aos fatores de personalidade e de psicologia, ao tempo que mantêm-se o interesse por pesquisas de intenção empreendedora aplicada a questões de gêneros.

Figura 6 - Comparativo entre pesquisa de Liñan e Fayolle (2015) e a atual, Grupo 3

\section{Grupo 03}

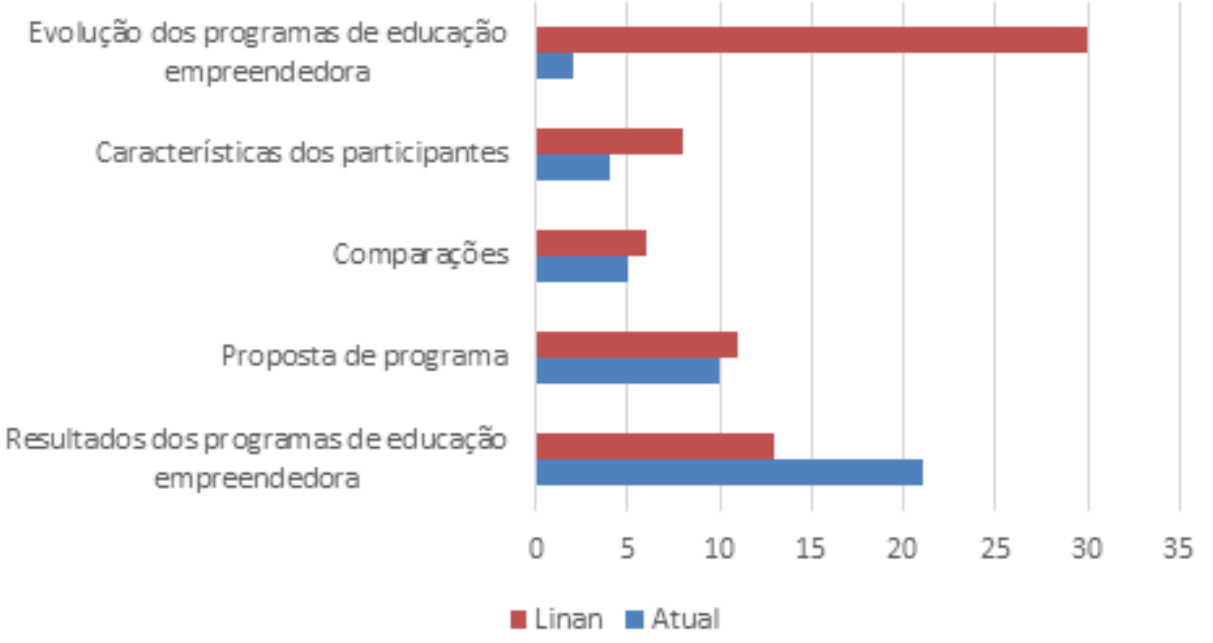

Fonte: Dados da pesquisa (2019). 
No grupo 3, Liñan e Fayolle (2015) detectam uma grande quantidade de pesquisas relacionadas a evolução dos programas de educação empreendedora. No entanto, este subgrupo já não é mais destaque nos anos de 2014 a 2018. Nestes anos o interesse das pesquisas passou-se a ser nos resultados dos programas de Educação Empreendedora (EE). Este cenário deve-se ao fato da grande expansão de programas e técnicas de EE nas Instituições de Ensino Superior e a aplicação em diversos cursos e áreas. Desde a administração, o que já era comum nos anos de 2004 a 2013, até cursos como enfermagem, engenharia, dentre outros.

Figura 7 - Comparativo entre pesquisa de Liñan e Fayolle (2015) e a atual, Grupos 4, 5 e 6

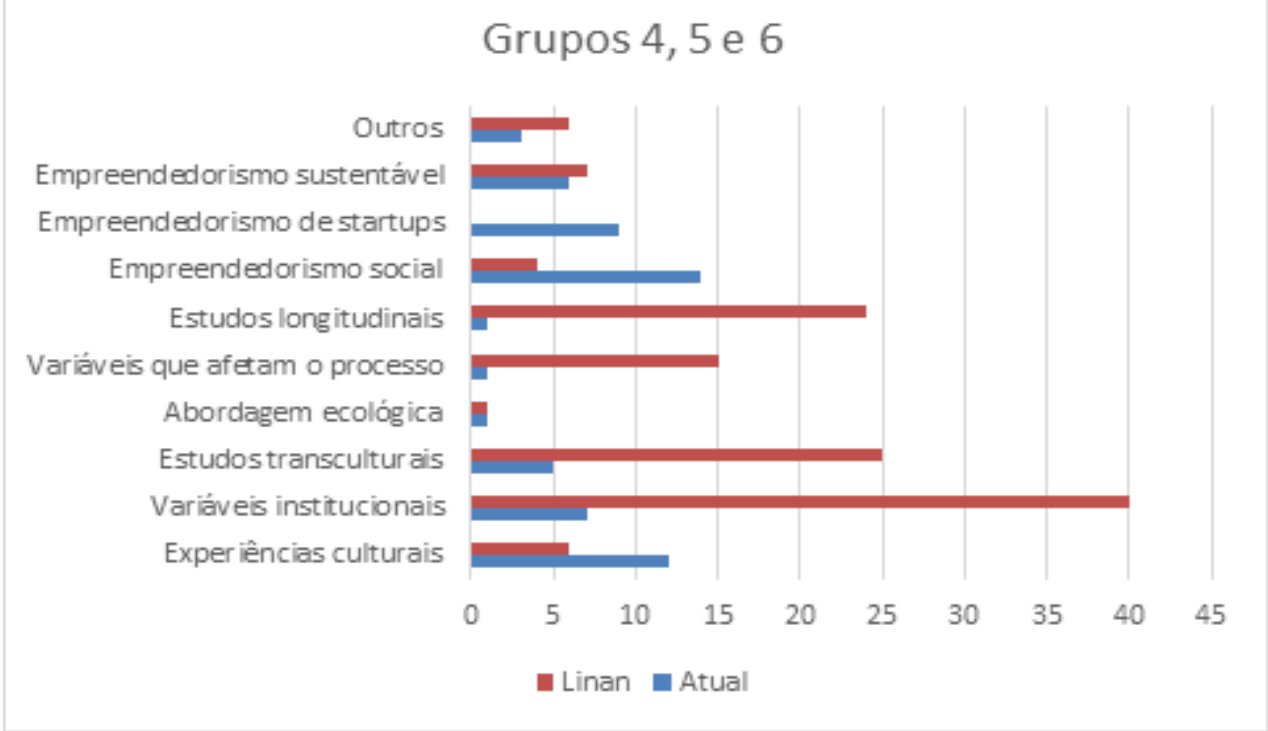

Fonte: Dados da pesquisa (2019).

Nos grupos seguintes, 4,5 e 6 percebe-se o crescimento das pesquisas relacionadas a experiências culturais. Comparativos da intenção empreendedora em diversos países e experiências de empreender em culturais diversas são destaques na pesquisa. É notório também a redução no número de pesquisas relacionadas as variáveis institucionais, ou seja, pesquisas que analisam a influência das instituições na intenção empreendedora.

A Tabela 3 apresenta uma síntese da pesquisa de IE nos últimos cinco anos.

Tabela 03 - Intenção empreendedora por grupos ao longo dos anos

\begin{tabular}{c|c|c|c|c|c|c}
\hline Grupo & 2014 & 2015 & 2016 & 2017 & 2018 & Total Geral \\
\hline G1 & 10 & 22 & 24 & 26 & 42 & 124 \\
\hline G2 & 4 & 7 & 10 & 11 & 12 & 44 \\
\hline G3 & 1 & 8 & 7 & 9 & 17 & 42 \\
\hline G4 & 2 & 1 & 7 & 9 & 6 & 25 \\
\hline G5 & - & 1 & - & 1 & - & 2 \\
\hline Total Geral & 18 & 41 & 57 & 64 & 89 & 269 \\
\hline
\end{tabular}

Fonte: Dados da pesquisa (2019). 
Com destaque para as pesquisas do Grupo 1, que abordam, de forma empírica, a aplicação do modelo de IE a diferentes grupos e culturas. Na Tabela 3 analisou-se a evolução quantitativa da pesquisa em Intenção Empreendedora nos anos de 2014 a 2018. Destaca-se o crescimento exponencial no ano de 2018 em todos os grupos de classificação de Liñan e Faylle (2015), em especial no grupo 1, com 42 artigos publicados em sua maioria aplicando o modelo de intenção empreendedora a grupos diversos. O grupo 3 é o segundo com maior quantidade de publicações, são 15 artigos sobre Educação Empreendedora.

\section{Considerações finais}

Tendo em vista os objetivos desta pesquisa, constatou-se a evolução dos estudos de Intenção Empreendedora no mundo. Enquanto Liñan e Fayolle (2015) analisaram 409 artigos em um período de 10 anos (2004 a 2013), analisou-se nesta pesquisa, no período de cinco anos (2014-2018), 269 artigos. Os números refletem a tendência expressiva de duplicar a quantidade de publicações nos próximos cinco anos e do surgimento de novos subgrupos.

Constatou-se também que a classificação realizada por Liñan e Fayolle (2015) é suficiente também para a categorização das pesquisas dos últimos cinco anos. No entanto, no Grupo 6, grupo que estuda as novas pesquisas, detectou-se o surgimento de mais um subgrupo, o empreendedorismo de startup.

Enquanto isto, os demais subgrupos do grupo 6, ainda não apresentaram quantidade de pesquisas suficiente para serem divididos em novos grupos. Observou-se uma evolução quanto a pesquisa de empreendedorismo social e manteve-se estável a quantidade de publicações sobre empreendedorismo sustentável. A aposta destes autores é que nos próximos anos a pesquisa de empreendedorismo social ganhe grande relevância e passe a ser um novo grupo de classificação da área.

Assim como, a pesquisa em empreendedorismo de startup ganhará grande relevância, pois nos últimos cinco anos já apresentou nove estudos de impacto e ultrapassou o quantitativo de publicações se comparado ao empreendedorismo sustentável.

Percebe-se que os estudos de empreendedorismo de startup aponta para diversos caminhos, como teste de modelo, aplicação de novas variáveis, estudos transculturais, análise da educação empreendedora de startup, dentre outros. Desta forma, sugere-se um conjunto de novas pesquisas que contribuirão para o desenvolvimento da área, são elas:

- $\quad$ Avaliar a educação empreendedora voltada a startups, uma vez que, em sua maioria, os programas de empreendedorismo destacam empresas tradicionais. em diferentes países.

- Criar modelo que permita estudos transculturais de ecossistemas de startups.

- Analisar e comparar diferentes ecossistemas de startups.

Esta é uma das principais contribuições desta pesquisa, verificar que a categorização efetuada por Liñan e Fayolle (2015) é suficiente para alocar a grande maioria das pesquisas de intenção empreendedora, exceto as abordagens de intenção de startup. Fato que fez surgir uma nova subcategoria que se apresenta como um novo caminho nas pesquisas de intenção empreendedora. 
Este estudo tem suas limitações quanto a abrangência de mais bases de dados e concentração de todas as reais publicações no período de 2014 a 2018. No entanto, atinge seu objetivo em dar prosseguimento a pesquisa de Liñan e Fayolle (2015), nas mesmas bases de dados utilizadas pelos autores.

\section{Referências}

ACS, Zoltan et al. Public policy to promote entrepreneurship: a call to arms. Small Business Economics, v. 47, n. 1, p. 35-51, 2016.

AJZEN, Icek. The theory of planned behavior. Organizational behavior and human decision processes, v. 50, n. 2, p. 179-211, 1991.

BARBA-SÁNCHEZ, Virginia; ATIENZA-SAHUQUILLO, Carlos. Entrepreneurial intention among engineering students: The role of entrepreneurship education. European Research on Management and Business Economics, v. 24, n. 1, p. 53-61, 2018.

BERGMANN, Heiko; HUNDT, Christian; STERNBERG, Rolf. What makes student entrepreneurs? On the relevance (and irrelevance) of the university and the regional context for student start-ups. Small Business Economics, v. 47, n. 1, p. 53-76, 2016.

BIRAGLIA, Alessandro; KADILE, Vita. The role of entrepreneurial passion and creativity in developing entrepreneurial intentions: Insights from American homebrewers. Journal of Small Business Management, v. 55, n. 1, p. 170-188, 2017.

CODURAS, Alicia; SAIZ-ALVAREZ, José Manuel; RUIZ, Jesús. Measuring readiness for entrepreneurship: An information tool proposal. Journal of Innovation \& Knowledge, v. 1, n. 2, p. 99-108, 2016.

COSTA, Sílvia F. et al. Recognizing opportunities across campus: The effects of cognitive training and entrepreneurial passion on the business opportunity prototype. Journal of Small Business Management, v. 56, n. 1, p. 51-75, 2018.

DE PILLIS, Emmeline; REARDON, Kathleen K. The influence of personality traits and persuasive messages on entrepreneurial intention: A cross-cultural comparison. Career Development International, v. 12, n. 4, p. 382-396, 2007.

EKPE, Isidore et al. Lean start-up awareness and effect on entrepreneurial intentions among Malaysian youths. International Journal of Management in Education, v. 12, n. 1, p. 5769, 2018.

JHA, Srivardhini K. Entrepreneurial ecosystem in India: Taking stock and looking ahead. IIMB management review, v. 30, n. 2, p. 179-188, 2018.

KAUTONEN, Teemu; VAN GELDEREN, Marco; FINK, Matthias. Robustness of the theory of planned behavior in predicting entrepreneurial intentions and actions. Entrepreneurship Theory and Practice, v. 39, n. 3, p. 655-674, 2015.

KRISTIANSEN, Stein; INDARTI, Nurul. Entrepreneurial intention among Indonesian and Norwegian students. Journal of Enterprising Culture, v. 12, n. 01, p. 55-78, 2004. 
KRUEGER, Norris F.; CARSRUD, Alan L. Entrepreneurial intentions: applying the theory of planned behaviour. Entrepreneurship \& Regional Development, v. 5, n. 4, p. 315-330, 1993.

LANERO, Ana; VAZQUEZ, Jose-Luis. A social cognitive model of entrepreneurial intentions in university students. Anales de Psicología, v. 31, n. 1, p. 243, 2015.

LIÑÁN, Francisco; FAYOLLE, Alain. A systematic literature review on entrepreneurial intentions: citation, thematic analyses, and research agenda. International Entrepreneurship and Management Journal, v. 11, n. 4, p. 907-933, 2015.

SHAPERO, Albert. The entrepreneurial event. CA Kent (ed) The Enviroment for Entrepreneurship. Lexington, Mass.: Lexington Books, 1984.

MENOZZI, Davide; FIORAVANZI, Martina; DONATI, Michele. Farmer's motivation to adopt sustainable agricultural practices. Bio-based and Applied Economics Journal, v. 4, n. 1050-2016-85714, p. 125-147, 2015.

MIRANDA, Francisco Javier; CHAMORRO-MERA, Antonio; RUBIO, Sergio. Academic entrepreneurship in Spanish universities: An analysis of the determinants of entrepreneurial intention. European Research on Management and Business Economics, v. 23, n. 2, p. 113-122, 2017.

SAEED, Saadat et al. The role of perceived university support in the formation of students' entrepreneurial intention. Journal of small business management, v. 53, n. 4, p. 1127-1145, 2015.

SHIROKOVA, Galina; TSUKANOVA, Tatyana; MORRIS, Michael H. The moderating role of national culture in the relationship between university entrepreneurship offerings and student start-up activity: an embeddedness perspective. Journal of Small Business Management, v. 56, n. 1, p. 103-130, 2018.

STANIEWSKI, Marcin; AWRUK, Katarzyna. Start-up intentions of potential entrepreneursthe contribution of hope to success. Economic research-Ekonomska istraživanja, v. 29, n. 1, p. 233-249, 2016.

TRAN, Anh TP; VON KORFLESCH, Harald. A conceptual model of social entrepreneurial intention based on the social cognitive career theory. Asia Pacific Journal of Innovation and Entrepreneurship, v. 10, n. 1, p. 17-38, 2016.

WELSH, Dianne HB; TULLAR, William L.; NEMATI, Hamid. Entrepreneurship education: Process, method, or both?. Journal of Innovation \& Knowledge, v. 1, n. 3, p. 125-132, 2016.

XIAO, Li; LARSON, Mitch; NORTH, David. Influence of entrepreneurial teams on the growth orientation of early-stage high-tech SMEs in China: Multiple measures of performance. The International Journal of Entrepreneurship and Innovation, v. 14, n. 1, p. 29-38, 2013. 